\title{
EL FUTURO DE LA JUSTICIA CONSTITUCIONAL'
}

\section{The future of constitucional justice}

\author{
MANUEL ARAGÓN REYES ${ }^{2}$ \\ Universidad Autónoma de Madrid \\ manuel.aragon@uam.es
}

\author{
Cómo citar/Citation \\ Aragón Reyes, M. (2019). \\ El futuro de la justicia constitucional. \\ Anuario Iberoamericano de Justicia Constitucional, 23(1), $11-41$. \\ doi: https://doi.org/10.18042/cepc/aijc.23.01
}

\section{Resumen}

El objetivo de este trabajo es exponer el futuro de la justicia constitucional desde el enfoque de los desafíos a los que se enfrenta en el futuro inmediato. En particular, el análisis se centra en la hipótesis de una justicia constitucional multinivel y la necesidad de que los Estados se integren en ella, para reforzar su eficacia. Todo ello, sin olvidar el sentido de la justicia constitucional y el rol que desempeña en el Estado de derecho. El trabajo concluye con una reflexión sobre el Tribunal Constitucional español y sus reformas recientes para asegurar el cumplimiento de sus resoluciones.

1 Una primera versión de este trabajo se corresponde con mi discurso de ingreso, como académico de honor, en la Real Academia Sevillana de Legislación y Jurisprudencia, pronunciado en noviembre de 2016. Ahora he incorporado, además de algunos cambios, otras reflexiones posteriores. He eludido, salvo excepciones, las citas bibliográficas, suficientemente conocidas y que, por lo demás, pueden encontrarse en los diversos escritos sobre justicia constitucional contenidos en mi libro (Aragón, 2013).

2 Catedrático emérito de Derecho Constitucional de la Universidad Autónoma de Madrid, magistrado emérito del Tribunal Constitucional y académico de número de la Real Academia de Jurisprudencia y Legislación de España. 


\section{Palabras clave}

Justicia constitucional; multinivel; Estado de derecho; futuro.

\section{Abstract}

The aim of this work is to expose the future of constitutional justice from the approach of the challenges it faces in the immediate future. In particular, the analysis focuses on the hypothesis of multilevel constitutional justice and the need for States to integrate into it, to reinforce its effectiveness. All this, without forgetting the sense of constitutional justice and the role it plays in the rule of law. The work concludes with a reflection on the Spanish Constitutional Court and its recent reforms to ensure compliance with its resolutions.

\section{Keywords}

Constitutional justice; multilevel; rule of law; future. 


\section{SUMARIO}

I. INTRODUCCIÓN: CONSTITUCIÓN Y JUSTICIA CONSTITUCIONAL. II. EL ACTIVISMO JUDICIAL. III. UNA DISCUSIÓN REITERADA Y, CASI SIEMPRE, MAL PLANTEADA: JUSTICIA CONSTITUCIONAL Y DEMOCRACIA: 1. Planteamiento. 2. La democracia constitucional. 3. La justicia constitucional: género y especies. 4. La llamada «objeción democrática» a la justicia constitucional y la necesidad de distinguir entre la democracia «de» la constitución y la democracia «en» la constitución. 5. La interpretación constitucional. 6. Los significados procedimental y sustantivo de la democracia. Justicia constitucional y reforma de la Constitución. 7. El problema de las relaciones entre justicia constitucional y democracia no radica tanto en la existencia de la primera, sino en su modo de actuar. IV. EL FUTURO DE LA JUSTICIA CONSTITUCIONAL ESPAÑOLA: 1. Justicia constitucional y jurisdicción constitucional. 2. El futuro de la justicia constitucional desempeñada por los jueces y tribunales ordinarios. 3. El futuro de la justicia constitucional desempeñada por el Tribunal Constitucional. V. CONCLUSIONES. Biblografía.

\section{INTRODUCCIÓN: CONSTITUCIÓN Y JUSTICIA CONSTITUCIONAL}

Por exigencias de la teoría, que la práctica ha venido confirmando, cabe sostener que constitución y justicia constitucional son hoy realidades inseparables. Ello es claro en lo que podríamos llamar constituciones modernas, «racional-normativas» en términos de García-Pelayo, pero también lo es en el único ejemplo de constitución antigua o «histórica» que todavía se conserva: la del Reino Unido. Allí la Constitución, o al menos sus partes destinadas a regular las relaciones de los ciudadanos con el poder, es, y siempre ha sido, derecho aplicable por los jueces, aunque esa Constitución no goce del carácter supralegal que sí tienen las constituciones modernas. Cuando, a través de un largo proceso, las constitucionales «racional-normativas» fueron desplegando la potencialidad inherente a sus postulados (primero en los Estados Unidos de América y después en Europa), que no eran otros que la soberanía del pueblo, los derechos fundamentales y la división de poderes, quedó patente que solo concibiendo la constitución como norma jurídica suprema y dotando de eficacia a esa supremacía jurídica, la constitución podría regir efectivamente la vida de una comunidad. 
Partir, pues, de que la constitución es derecho significa aceptar que los jueces deberán aplicarla, pues no hay derecho sin la garantía judicial de su cumplimiento, y eso exige, necesariamente, atribuir esa garantía a órganos de naturaleza jurisdiccional. Y efectivamente, allí donde hay una auténtica constitución, lo que hoy significa una constitución normativa, que regula un Estado democrático de derecho, los jueces y tribunales controlan la constitucionalidad de las demás normas del ordenamiento y de los actos que en su aplicación se realizan. La justicia constitucional, en suma, no es otra cosa que la aplicación jurisdiccional de la constitución. En algunos países esa justicia la desempeñan todos los jueces y tribunales, sea cual sea la norma o acto sometido a su control. Ese modelo de justicia constitucional es el que suele calificarse como de jurisdicción difusa. En otros países, sin perjuicio de que también todos los jueces y tribunales aplican la constitución, se atribuye en exclusiva a un solo órgano jurisdiccional, un tribunal constitucional, el control de constitucionalidad de las leyes. Es el modelo también denominado de jurisdicción concentrada, o europeo, porque aquí nació aunque se ha extendido a otras zonas del mundo.

Ese es el presente. El futuro de la justicia constitucional no es otro, pues, que el futuro de la constitución, que es lo mismo que decir hoy del Estado constitucional y democrático de derecho. Las transformaciones que, como consecuencia de los procesos de supraestatalización, en unos casos, y de globalización, en todos, esa forma de Estado está experimentando en los últimos tiempos no suponen por sí solas que la justicia constitucional desaparezca, solo que está obligada a operar en ámbitos más extensos y complejos. Por otra parte, los peligros que ahora rondan a aquella forma de Estado, representados por los fundamentalismos identitarios, los populismos y los nacionalismos excluyentes, que pretenden acabar con ella, con ser ciertos y graves, confío en que no logren sus objetivos y, en tal sentido, si el Estado constitucional y democrático de derecho se mantiene en el futuro, seguirá manteniéndose, sin duda, la justicia constitucional.

Todo lo que acabo de decir no significa desconocer los defectos que esa justicia constitucional pueda tener, que sí los tiene. Lo único que he pretendido en esta especie de introducción es señalar, de manera general, o más exactamente, conceptual, el carácter indisociable de constitución y justicia constitucional, avalado hoy, como dije al principio, por la teoría y la práctica. Cosa bien distinta es examinar el estado en que se encuentra en la actualidad la justicia constitucional y, en ese plano histórico y concreto, señalar algunas de sus disfunciones y proponer determinadas reformas para eliminarlas o atenuarlas, pues si el futuro de aquella, como institución, no lo veo radicalmente comprometido, sí creo que ese futuro transcurrirá en mejores condiciones 
si se erradican algunos de los defectos que hoy aquejan a la aplicación de la constitución por los órganos jurisdiccionales.

\section{EL ACTIVISMO JUDICIAL}

El principal de esos defectos creo que es el activismo judicial. Pero antes de referirme a él debo aclarar que por activismo judicial no entiendo los casos, lamentables, de que en algunas ocasiones o lugares la justicia constitucional haya producido decisiones fundadas en razones políticas y no jurídicas. Eso no es activismo, sino incumplimiento grave de la obligación constitucional de juzgar conforme a derecho y no por motivos ideológicos o morales. Que los tribunales que han de aplicar la constitución puedan tener en cuenta las consecuencias políticas de sus decisiones es una cosa, perfectamente lógica, y otra distinta y rechazable es que la decisión que adopten, incluso tomando en consideración ese factor, no se argumente con razones jurídicas. Por fortuna, en los países con justicia constitucional consolidada resoluciones así, tan contrarias a la función jurisdiccional, no suelen producirse. Por activismo entiendo otra cosa: la laxitud interpretativa de los textos jurídicos y la suplantación por el órgano jurisdiccional de las competencias de otros poderes del Estado.

Ese activismo sí es relativamente frecuente, y debe criticarse. En cuanto a la laxitud interpretativa, me refiero a la que puede recaer tanto sobre la constitución como sobre las leyes, ya que a la justicia constitucional le corresponde la interpretación de la constitución y la interpretación constitucional de la ley. Sobre ambos textos ha de producirse, pues, una actividad interpretadora que debe tener límites, pues, de lo contrario, los órganos de justicia constitucional no solo podrían suplantar al constituyente, sino también al legislador.

Es cierto que la interpretación de la constitución, por el amplio grado de abstracción y generalidad inherentes a muchas de sus prescripciones, lleva consigo una alta dosis de recreación y adaptación de la norma a nuevas circunstancias, pero también es cierto que esa capacidad tiene un límite, que me parece que no es otro que el derivado del significado unívoco que algunos de los términos normativos puedan tener. Cuando ello se desconoce, haciéndole decir a la constitución lo contrario de lo que literalmente dice, no se está interpretando la constitución, sino modificándola sin seguir su propio procedimiento de reforma. Los órganos de la justicia constitucional cooperan con el constituyente, por supuesto, pero no deben suplantarlo.

$Y$ en lo que se refiere a la interpretación constitucional de la ley, para adaptar su sentido a lo previsto en la constitución, esa tarea, de obligado cumplimiento, no debe llevar al extremo de evitar la anulación o inaplicación de la ley mediante la operación de hacerle decir lo contrario de lo que la ley dice, 
sencillamente porque entonces a quien se está sustituyente es al propio legislador. En un Estado constitucional, los órganos de la justicia constitucional debe ejercen jurisdicción, no legislación.

De este activismo judicial, de este criticable desvío de la justicia constitucional, sí que contamos con indudables ejemplos de decisiones jurisdiccionales en España y fuera de ella, que no es preciso ahora identificar, dado el carácter general de las reflexiones que estoy formulando en esta parte del presente trabajo. Solo debo apuntar que de ese activismo debe huirse mediante una seria reconsideración acerca de los límites de la interpretación constitucional y de los excesos de las sentencias llamadas interpretativas, reconsideración necesaria si no se quiere poner en peligro la propia legitimidad de los órganos de la justicia constitucional.

Conectado con el problema anterior, de tal manera que es solo una variante de él, cabe señalar al activismo caracterizado por la actuación de los órganos de la justicia constitucional como verdaderos agentes de cambio social, formulando en sus decisiones programas concretos de políticas públicas y obligando a los poderes políticos (Ejecutivo y Legislativo) a su realización. Eso sucede en las llamadas, con discutible terminología, sentencias «estructurales», nombre que ha hecho fortuna en algún sector de la doctrina constitucional iberoamericana (Rodríguez Garavito y Rodríguez Franco, 2010). Tales sentencias, con la pretensión de asegurar la efectiva protección de los derechos (preferentemente sociales, pero no solo ellos) de extensos grupos de personas, imponen, pues, al Estado amplias obligaciones de hacer (de tipo normativo e incluso ejecutivo), reservándose, a veces, el control de su cumplimiento.

Este tipo de activismo, o si se quiere de judicialización de la política, aunque lo han practicado en ocasiones órganos judiciales ordinarios, es en la jurisdicción constitucional donde ha tenido su mayor proyección. Bien es cierto que solo en determinados países, especialmente en Colombia en los últimos tiempos ${ }^{3}$. No obstante, la existencia de resoluciones judiciales que ordenan a los poderes públicos la realización de un programa normativo no es algo nuevo, pues ya se habían producido parecidas sentencias (aunque con mandatos menos detallados e incisivos) en jurisdicciones constitucionales o análogas de otros lugares. Así, un ejemplo próximo podría ser el de las llamadas «sentencias piloto» del Tribunal Europeo de Derechos Humanos, en las

3 Entre otras, sentencias del Tribunal Constitucional colombiano de 1 de agosto de 2002, referencia T-595 de 2002; de 22 de enero de 2004, referencia T-025 de 2004; de 31 de julio de 2008, referencia T-760 de 2008, y de 15 de diciembre de 2008, referencia T-1258 de 2008. 
que se impone a un Estado el establecimiento de determinadas medidas ${ }^{4}$, o el de sentencias del Tribunal Supremo norteamericano que marcan estándares de protección de derechos que las autoridades deben cumplir ${ }^{5}$, o el de sentencias del Tribunal Constitucional de Sudáfrica en el mismo sentido ${ }^{6}$.

El principal problema de este tipo de sentencias radica en el riesgo de desnaturalización de la función jurisdiccional, que está para controlar a los poderes públicos, pero no para sustituirlos. Y ese riesgo se encuentra unido al del mayor o menor grado de concreción de sus mandatos de hacer. Que los tribunales (me refiero ahora solo a los que ejercen la jurisdicción constitucional) en sus decisiones protegiendo un derecho han de «adoptar las medidas apropiadas, en su caso, para su conservación» (como expresa, por cierto, el art. 55.1.c de la Ley Orgánica del Tribunal Constitucional español —en adelante LOTC-) es algo claro, pacífico y debido. Pero cosa bien distinta es que impongan un programa detallado de regulación general (o para grupos o clases amplias de personas) de ese derecho para hacerlo efectivo (y en caso de un derecho social, de una política pública detallada para lograrlo). Y no es un tema que afecte solo a la legitimidad del órgano jurisdiccional, sino también a la eficacia de sus decisiones, ya que esta será siempre, de modo inevitable, inversamente proporcional al mayor o menor grado de concreción de las medidas que la sentencia establezca.

\section{UNA DISCUSIÓN REITERADA Y, CASI SIEMPRE, MAL PLANTEADA: JUSTICIA CONSTITUCIONAL Y DEMOCRACIA}

\section{PLANTEAMIENTO}

Hablar de «justicia constitucional y democracia» obliga a poner de manifiesto, desde el primer momento, cuál es el auténtico fondo de esa relación

4 Por señalar una: la STEDH de 19 de junio de 2006, caso Hutten-Czapska vs. Polonia.

5 Así, por ejemplo, la conocida Sentencia de 17 de mayo de 1954, caso 347 US 483 (1954), asunto Brown vs. Board of Education, complementada por la Brown II, de 31 de mayo de 1955, caso 349 US 294 (1955) del mismo asunto. De todos modos, el Tribunal Supremo ha limitado extraordinariamente ese tipo de resoluciones, rechazando que se concreten o detallen en exceso tales estándares, pues ello conduciría a una «desmedida intervención de los jueces» en los otros poderes del Estado (Sentencia de 14 de mayo de 1979, caso 441 US 520 [1979], asunto Bell vs. Wolfish).

6 Así la pionera Sentencia de 4 de octubre de 2000, caso CCT 11/00, asunto Irene Grootboom and Others vs. The Government of the Republic of South Africa and Others. 
problemática, tan mal entendida o tan confusamente entendida, a veces, por algunos sectores del derecho público e incluso de la filosofía del derecho.

$\mathrm{El}$ fondo al que antes me refería consiste en que para relacionar justicia constitucional y democracia es necesario partir de un significado muy preciso de ambos términos. Así, por lo que se refiere a la democracia, no es intelectualmente válido apelar a un concepto abstracto de democracia, sino a un concreto entendimiento de ella: el de la democracia constitucional. Tampoco, bajo el nombre de justicia constitucional, cabe referirse a cualquier modo de control de constitucionalidad, sino solo al que se le encomienda a órganos jurisdiccionales independientes, jurídicamente solventes y que adoptan sus decisiones fundadas únicamente en razones de derecho. Es a partir, pues, de tales significados específicos cuando puede enfocarse debidamente la relación que une a ambos términos.

Por ello, de manera previa al examen de la naturaleza de aquella relación, conviene dejar bien claro lo que esos términos significan, comenzando por el de la democracia constitucional.

\section{LA DEMOCRACIA CONSTITUCIONAL}

La democracia, como forma de organización y ejercicio del poder en una comunidad política, solo ha podido verse garantizada cuando se ha formalizado a través de la constitución, única norma que asegura la soberanía del pueblo e impide, por ello, que el poder del Estado vulnere los derechos de libertad e igualdad de los ciudadanos cotitulares de esa soberanía. De ahí que no haya más constitución auténtica que la constitución democrática ni más democracia auténtica que la democracia garantizada por la constitución. En realidad, ello no significa otra cosa que lo que hace ya casi dos siglos y medio estableció la Declaración francesa de Derechos del Hombre y del Ciudadano, que, después de proclamar que no hay más soberanía que la de la nación, estableció, en su art. 16, que todo país en el que no estén divididos los poderes ni garantizados los derechos de los ciudadanos carece de constitución. Aparecía así el Estado constitucional como nueva forma política histórica, basada en la existencia de una norma suprema, la constitución, emanada del poder constituyente soberano, cuyo objeto era la limitación funcional (división de poderes), temporal (elecciones periódicas) y material (garantía de los derechos fundamentales) del poder del Estado para asegurar la propia soberanía del pueblo, pues solo un pueblo libre puede ser soberano y solo un pueblo es libre si los ciudadanos que lo componen tienen asegurada su libertad.

La concepción formal de constitución (derecho supremo que vincula a todos los poderes públicos) y la concepción material de constitución (norma que tiene por objeto la limitación del poder en garantía de la libertad) aparecen, 
así, indisolublemente asociadas. Para la forma política nueva, racionalizada, llamada Estado constitucional, que surge en Norteamérica y Europa a finales del siglo XviII, la idea misma de constitución es la que permitiría que en aquella forma política no fuese realidad lo que Rousseau decía de los ingleses, que se creen libres, pero se equivocan, pues solo lo son en el momento de votar, quedando sometidos después a un poder tan omnímodo como el de la monarquía absoluta: el del Parlamento. Sin perjuicio de que el constitucionalismo británico (y ello difícilmente podía ser advertido por Rousseau) haya sido capaz hasta hoy de preservar la libertad política de los ingleses, no mediante la garantía de una constitución supralegal, de la que carecen, sino de las garantías políticas y sociales que sí han servido allí para mantener su constitución histórica y prescriptiva.

Lo que importa subrayar es que la idea de que no hay democracia sin constitución, ni constitución sin democracia, está en los mismos orígenes del Estado constitucional «moderno» (a diferencia del «antiguo» y consuetudinario que surgió a través de los siglos en el Reino Unido) y fue haciéndose realidad práctica, en determinados países del mundo entre los que nos encontramos, en el transcurso de un proceso histórico que, a lo largo de casi siglo y medio, logró fundir liberalismo y democracia, no solo políticamente, sino también jurídicamente mediante el instrumento de la constitución. La democracia constitucional acabó siendo así una democracia asegurada por la constitución, lo que significa que no cabe apelar a la democracia por encima o al margen de la constitución, dado que solo dentro de ella la democracia se encuentra garantizada.

\section{LA JUSTICIA CONSTITUCIONAL: GÉNERO Y ESPECIES}

Como es obvio, la democracia constitucional tiene como presupuesto la vigencia efectiva de la constitución como norma suprema del ordenamiento. Y como no hay derecho sin justicia que lo aplique en última instancia, únicamente si existe una justicia capaz de hacer cumplir la constitución la democracia constitucional está garantizada. Por ello, también desde los comienzos del constitucionalismo moderno, "racionalizado", surgió el convencimiento de que la justicia constitucional era un elemento necesario de la idea misma de constitución, aunque su implantación práctica haya sido también fruto de un largo proceso histórico que se inició primero en Estados Unidos, que se extendería después a algunos países iberoamericanos y que acabó imponiéndose en Europa (e incluso en algunos otros lugares del mundo) a lo largo del pasado siglo $\mathrm{xx}$, dando lugar a un fenómeno cuyas características actuales es conveniente recordar, porque si bien a partir del significado de «democracia constitucional» ya es suficiente para encuadrar uno de los términos de la relación a que nos 
estamos refiriendo, es preciso, sin embargo, detallar algo más en lo que afecta al otro término, «justicia constitucional», dada la variedad y complejidad de los modelos en que esta se ha desarrollado.

En la actualidad, dentro del mismo género (no hay otro válido) de justicia constitucional como institución jurisdiccional de control de la efectividad de la constitución, encontramos diversas especies: modelos de jurisdicción concentrada (al estilo europeo), de jurisdicción difusa (el ejemplo norteamericano, que también se extendió a otros lugares, entre ellos en Iberoamérica) y mixta (coexistencia entre el control concentrado y el control difuso, especie muy frecuente hoy en países iberoamericanos). No obstante, esta multiplicidad, en el fondo, es menos variada de lo que suponen esas meras descripciones.

De un lado, porque en los modelos de jurisdicción difusa se da hoy una relativa aproximación a los modelos de jurisdicción concentrada, al menos en lo que se refiere a los efectos generales de algunas de las resoluciones que en esa jurisdicción difusa se adoptan y a la existencia en ella, en determinados casos, de acciones colectivas, y no solo individuales, de acceso a la justicia constitucional, aparte de la función unificadora que genera el precedente.

De otro lado, porque en los modelos de jurisdicción concentrada la constitución también la aplican los jueces y tribunales ordinarios, aunque esté encomendado únicamente a los tribunales constitucionales el control de la constitucionalidad de la ley (no así en los Estados de la Unión Europea el control de la adecuación de la ley interna al derecho de la Unión, confiado a todos los jueces y tribunales ordinarios en una suerte de jurisdicción difusa) y porque incluso, allí donde existe el recurso de amparo, los ciudadanos pueden acceder directamente al tribunal constitucional.

Y por último, porque en los modelos mixtos hay una mezcla de jurisdicción concentrada y de jurisdicción difusa en el control de la ley, lo que ha originado que, pese a existir diferencias, ya no pueda hablarse, con propiedad, de una distinción radical entre los diversos modelos de justicia constitucional.

De todos modos, y al margen de la aproximación entre los modelos, la transformación más profunda que hoy ha experimentado la justicia constitucional consiste en la existencia de instancias jurisdiccionales de control de constitucionalidad de ámbito internacional o supranacional, como sucede en Europa, con el Tribunal de Justicia de la Unión Europea y el Tribunal Europeo de Derechos Humanos, y en Iberoamérica, con el Tribunal Interamericano de Derechos Humanos. Instancias de auténtica justicia constitucional, dado que resuelven (o deben resolver) los procesos de que entienden a través de un razonamiento jurídico y no político, y que el parámetro de control que utilizan son normas materialmente constitucionales aunque formalmente hayan sido establecidas por tratados o convenios internacionales, ya sean el Tratado de 
la Unión Europea (y dentro de él la Carta de Derechos Fundamentales de la Unión Europea), el Convenio Europeo de Derechos Humanos o el Convenio Interamericano de Derechos Humanos. Instancias que, además, se superponen, en una relación de delicado equilibrio, a los órganos de justicia constitucional de los Estados nacionales.

Ahora bien, tanto en las instancias nacionales de control de constitucionalidad como en las aludidas instancias supranacionales, la estructura y función que las caracteriza es la misma: se trata de órganos de composición meritocrática (cuyos integrantes han de ser juristas de reconocida competencia), en los que el principio democrático solo opera indirectamente en su designación, y que tienen, no obstante, facultades de control de actos y normas adoptados por los poderes emanados de la representación popular. Esa aparente contradicción es la que ha conducido a que algunos, con escasa meditación, entiendan que existe una franca oposición entre democracia y justicia constitucional. Entendimiento viciado, creo, por un defecto de enfoque y por una inapropiada construcción teórica, que es de lo que ahora vamos a tratar.

\section{LA LLAMADA «OBJECIÓN DEMOCRÁTICA» A LA JUSTICIA CONSTITUCIONAL Y LA NECESIDAD DE DISTINGUIR ENTRE LA DEMOCRACIA «DE» LA CONSTITUCIÓN Y LA DEMOCRACIA «EN»LA CONSTITUCIÓN}

Como una especie de secuela de las viejas ideas de Carl Schmitt, que, frente a Kelsen, negaba el carácter jurídico de la justicia constitucional, ha vuelto a utilizarse en nuestro tiempo, y ha tenido cierta fortuna, el argumento de la ilegitimidad de un órgano estatal no democrático para controlar las decisiones de los órganos políticos democráticos. Esa es la base de la llamada «objeción democrática» a la justicia constitucional, al menos en su vertiente más simple, aunque también se haya extendido otra (cuyo origen, más que en Schmitt, está en Lambert) que, aceptando que la justicia constitucional es justicia y no política, discute la legitimidad de que unos jueces puedan controlar al legislador democrático, ya que entonces son aquellos los que "gobiernan» y no los representantes del pueblo, subvirtiendo de ese modo la división de poderes. En ambos casos cabe encontrar una evidente debilidad teórica. Simplemente porque se basan en un defectuoso entendimiento de la democracia constitucional.

Como ya se dijo más atrás, la democracia constitucional no significa otra cosa que el establecimiento de reglas de derecho que limitan el poder constituido, y ello, en una democracia, significa limitar el poder de la propia mayoría. Por eso, la capacidad de un órgano del Estado democrático, necesariamente judicial (como debe ser cualquier órgano que resuelva de manera 
definitiva las controversias en derecho), de anular las decisiones adoptadas por la propia mayoría democrática no es una paradoja real, sino únicamente aparente, pues el Estado constitucional democrático no deja de serlo, democrático, por el hecho de que la mayoría no pueda ser soberana. Al contrario, esa es la condición de la democracia constitucional, en la que solo el pueblo (y no sus representantes) ostenta la soberanía. De ahí que el Estado constitucional democrático se base en una distinción sin la cual tal forma de Estado carecería de sentido: la diferencia entre el poder constituyente y el poder constituido.

En ambos planos se proyecta el principio democrático, aunque no de igual manera. En el plano constituyente (democracia «de» la constitución), la democracia no puede sustentarse en la regla de la simple mayoría, sino en la regla del consenso, esto es, de exigencia de unas mayorías muy cualificadas; cosa obvia, puesto que la constitución garantiza derechos y estructuras que no pueden estar a la disposición del poder constituido, es decir, de las mayorías cambiantes que en cada momento se sucedan como consecuencia de los procesos electorales. Si así no fuera, la constitución desaparecería, dado que dejaría de ser una norma supralegal, y, entonces, como se expresó en frase afortunada y bien conocida, sería "una página en blanco que el legislador puede escribir a su capricho", lo que significaría, simplemente, que no habría constitución.

Una constitución es democrática porque emana democráticamente. Pero una constitución garantiza la democracia porque la preserva frente a la propia mayoría, en cuanto que establece unas prescripciones que la simple mayoría no puede cambiar. Unas prescripciones fundamentales (en su doble significado de superiores y de más importantes) que solo pueden ser acordadas por la democracia de consenso. Consenso que será obligatorio, en coherencia, para la reforma de la misma constitución. Esa es la base democrática de la rigidez constitucional.

Distinta es la proyección del principio democrático en el poder constituido, que opera a través de la regla de la mayoría y no del consenso, salvedad hecha de que algunas medidas que la propia constitución prevé deban adoptarse por mayorías superiores a la simple, así la emanación de determinadas leyes, pero siempre por una mayoría cualificada inferior a la que puede disponer de la constitución, pues de lo contrario se confundirían poder constituyente y poder constituido. Ese, el que se proyecta en el poder constituido, es el plano de la democracia «en» la constitución, esto es, el de la democracia que la constitución establece para la adopción de las decisiones ordinarias del Estado. Y esta segunda forma de proyección de la democracia no puede sobreponerse sobre aquella primera, de manera que la democracia «en» la constitución ha de atenerse a la democracia «de» la constitución. Para que ello sea así está precisamente la justicia constitucional, que tiene como función garantizar que 
el poder constituido no vulnera lo decidido por el poder constituyente. En tal sentido no solo resulta incorrecto entender que hay una oposición entre democracia y justicia constitucional, sino que debe afirmarse que es la justicia constitucional la que hace posible la propia democracia, esto es, la que garantiza que la democracia de consenso, que produjo la constitución y ha de regir sus reformas, no sea suplantada por la democracia de la mayoría, propia de las actuaciones del poder constituido.

En consecuencia, la democracia constitucional, en la que la democracia «en» la constitución está subordinada a la democracia «de» la constitución, exige que haya justicia constitucional. Justicia de jueces y no de políticos (lo que sería un contrasentido), pues es función «natural» de la jurisdicción resolver los conflictos entre normas (entre la constitución y las que componen el resto del ordenamiento). Si así no fuera tendría todo el sentido la conocida frase de Rousseau, ya citada más atrás, de que «los ingleses se creen libres, pero solo lo son el momento de votar». En la democracia constitucional la libertad de los ciudadanos está garantizada en todo tiempo porque la constitución limita el poder de la propia mayoría, es decir, porque el Parlamento no es soberano, que solo lo es el pueblo, que mediante la democracia de consenso estableció unas reglas que garantizan los derechos y limitan el poder y por ello no están a la plena disposición de los poderes constituidos, existiendo una instancia objetiva, de aplicación de la constitución, que tiene encomendada la custodia fiel de esas reglas.

A partir de este entendimiento, que considero correcto, la llamada «objeción democrática» a la justicia constitucional carece de legitimidad teórica. No es que no haya oposición entre justicia constitucional y democracia, es que la una requiere necesariamente de la otra. Ahora bien, precisamente porque la justicia constitucional no puede dejar de estar sometida a la propia constitución, es por lo que su función de custodia de ella ha de ser «fiel», esto es, limitarse a fundar en razones jurídicas sus decisiones de preservación de la constitución frente a los actos del poder constituido. Por ello, el problema de la relación entre democracia y justicia constitucional no puede residenciarse en la existencia misma de esa justicia, existencia que es necesaria, sino en el modo de actuación de la jurisdicción constitucional, en su modo de aplicación «fiel» de la constitución. De donde se desprende que el problema de la relación entre democracia y justicia constitucional, que es un problema cierto, donde se sitúa, exactamente, es en la interpretación constitucional, de manera que, para evitar la contradicción entre los dos términos de esa relación, aquella interpretación habrá de producirse de modo jurídicamente razonable, y por ello objetivable, y no a través de decisiones fundadas en un mero ejercicio de voluntad política de la que, por principio, la justicia constitucional carece, pues su única legitimidad reside en el derecho y no en la política, y por ello en el razonamiento jurídico 
que sirve de base a sus decisiones. Lo que nos lleva a examinar, aunque sea brevemente, el específico carácter de la interpretación constitucional.

\section{LA INTERPRETACIÓN CONSTITUCIONAL}

Ya, al hilo del activismo judicial, se apuntó más atrás que la interpretación constitucional es una de las claves para determinar con propiedad lo que tiene de genuina la función de la suprema interpretación y aplicación de la constitución y de la suprema interpretación y aplicación constitucional de las leyes. Ahora conviene extenderse sobre este asunto verdaderamente nuclear. Los tribunales constitucionales, o los supremos tribunales en los modelos de jurisdicción difusa, son los supremos intérpretes de la constitución, además de los supremos intérpretes de la constitucionalidad de la ley. De ahí que su doctrina, derivada del ejercicio de ambas funciones, sea vinculante para todos los poderes públicos $y$, en especial, para todos los jueces y tribunales ordinarios, que deberán interpretar la constitución y las leyes de acuerdo con lo establecido en dicha doctrina. Dicho ello, la cuestión principal, entonces, es la de los límites de la interpretación constitucional, pues, mediante ella, ni el supremo intérprete constitucional puede suplantar al poder constituyente ni sustituir al legislador, cuyos actos puede anular por inconstitucionales, por supuesto, pero no desvirtuarlos o sustituirlos. Por ello, ni puede hacer decir a la constitución lo contrario de lo que ella dice, pues para modificarla está el poder de reforma constitucional, no el poder jurisdiccional, ni, para salvar su constitucionalidad, hacerle decir a la ley lo que objetivamente ella no dice, pues si bien puede hacer de legislador negativo, no le cabe comportarse como legislador positivo suplantando el legítimo papel del legislador democrático. Esas reglas generales de los límites de la interpretación constitucional han de seguirse, desde luego, pero solo con enunciarlas no se resuelven los complejos problemas que la interpretación constitucional plantea.

$\mathrm{Y}$ tales problemas radican en la peculiaridad que, frente a la interpretación de las leyes, tiene la interpretación de la constitución, debida a la diferente naturaleza de que gozan la Constitución y la ley. La constitución es norma bien distinta de la ley no solo por razones de forma, en cuanto que la constitución es la norma suprema, a la que la ley está subordinada, sino también por razón de su contenido, en cuanto que la constitución está integrada, además de por reglas, por una amplia variedad de principios que, como tales, están enunciados con una alta dosis de generalidad y abstracción. Ello es consecuencia de la función que cumplen las constituciones modernas, que no solo determinan el funcionamiento del Estado, sino que proclaman valores y principios que han de regir en la totalidad de la vida social, más exactamente, en los diversos sectores del ordenamiento jurídico público y privado. Por eso se 
ha dicho en frase gráfica que hoy «por la constitución pasan todos los hilos del derecho». Una norma así, tan omnicomprensiva y al mismo tiempo tan sintética (pues de lo contrario se convertiría en un cuerpo legal de dimensiones incalculables aparte de dejar sin espacio suficiente al desarrollo constitucional y de correr el riesgo cierto de la obsolescencia), requiere de una interpretación muy especialmente cualificada.

$\mathrm{Si}$ interpretar la ley ya supone una actividad intelectual muy alejada de la vieja idea de que el intérprete ha de limitarse a ser la boca que pronuncia las palabras de la ley, dado que hoy (y creo que siempre) en las leyes existen enunciados que requieren de un proceso hermenéutico que encierra una dosis de actividad recreadora (aunque siempre limitada por las exigencias de la seguridad jurídica), interpretar la constitución eleva esa actividad recreadora de manera exponencial. En ambos casos, interpretación de la constitución e interpretación de la ley, no debe perderse de vista que si la interpretación de una norma es, en muchos supuestos, recreación de ella, lo que no cabe admitir (salvo en los sistemas de common law) es que, mediante la actividad interpretadora, el juez cree, ex nihilo, normas antes inexistentes. Mediante la interpretación de los enunciados normativos, las normas que cabe deducir de ellos se «descubren", pero no se «inventan».

Sin embargo, no es esta distinción de cantidad (más principios y más abstracción en la constitución que en la ley), sino una distinción de cualidad, la principal diferencia entre ambos textos normativos, derivada del hecho de que las indefiniciones de la ley pueden ser concretadas a la luz de su interpretación constitucional, mientras que las indefiniciones de la constitución no pueden serlo apelando a una norma superior a ella. Y en todo caso, cuando cabe, en alguna materia constitucional, apelar a una norma más alta desde el punto de vista de la jerarquía hermenéutica (no exactamente de la jerarquía normativa), como sucede en los supuestos de sumisión estatal a los tratados o convenios sobre derechos humanos ( $\mathrm{y}$ a la doctrina de las jurisdicciones internacionales o supranacionales que tienen encomendada su protección), los problemas interpretativos que tales normas planteen tampoco pueden resolverse apelando a otra norma más alta, que no la hay.

De manera que en el estrato ordinamental superior, las indefiniciones normativas que no puedan resolverse en el interior del texto da la disposición de que forman parte utilizando los métodos habituales de la interpretación jurídica únicamente cabe concretarlas elevándose del plano dogmático normativo y apelando a la teoría, esto es, a la teoría general de la constitución (de la que forma parte la teoría general de los derechos humanos). Solo intérpretes muy cualificados, capaces de poseer los suficientes conocimientos teóricos, pueden, en los casos difíciles, realizar una interpretación constitucional objetivada. Es decir, una interpretación fundada en el derecho y no en el arbitrio. Una in- 
terpretación razonada y razonable, capaz de ser contrastada en el seno de la comunidad jurídica.

A estas razones que explican la singularidad de la constitución y por lo mismo de la interpretación constitucional, se añade otra, también derivada de una última distinción entre constitución y ley: la que se sustenta en la garantía del pluralismo político como valor constitucional. La constitución, además de contener determinadas reglas cerradas, sin las cuales difícilmente podría servir de límite al legislador, ha de contener otras reglas abiertas, susceptibles de desarrollos legislativos distintos en función del propio pluralismo. De ahí que la interpretación de la constitución sea, también por este motivo, una interpretación distinta de la de la ley. En la constitución democrática (lo que significa democrática-pluralista) la ley no es ejecución de la constitución como el reglamento sí lo es de la ley, pues la constitución ampara que bajo su vigencia pueda haber políticas legislativas distintas en función de la mayoría que en cada momento gana las elecciones. Mayoría que no goza de una completa libertad, por supuesto, pues si así fuera no habría constitución, pero sí que ha de tener una esfera de discrecionalidad, siempre dentro de los límites sustantivos que la propia constitución ha marcado. Incluso en unas normas materiales tan significativas como las que enuncian los derechos fundamentales, la sumisión del legislador no lo es a la totalidad del ámbito en el que el derecho puede desarrollarse, sino al contenido esencial de ese derecho, que es el límite que, necesariamente, el legislador ha de respetar.

Ello convierte a la interpretación constitucional en una tarea delicada y de suma prudencia, pues no le compete cerrar aquello que el constituyente dejó abierto. Solo una cuidadosa exégesis del texto constitucional, capaz de discernir entre reglas cerradas y abiertas, capaz de combinar, en la teoría y en la práctica, los principios y valores que la constitución impone, sea cual sea la mayoría parlamentaria, y las cláusulas facultativas, que no obligatorias, que la constitución también contiene para garantizar la capacidad de acción de esa misma mayoría, puede realizar con éxito aquella tarea. Y hacerlo de manera que la interpretación constitucional resultante no pierda su ineludible condición de objetividad mediante una argumentación razonable capaz de ser compartida, o criticada, a partir de los argumentos que el derecho, y no la política, proporciona.

Las características antes aludidas no hacen desaparecer la naturaleza de norma jurídica que la constitución posee (y en tal sentido no es teóricamente aceptable la idea de Schmitt de que la constitución es norma política y no exactamente norma jurídica), pero sí es cierto que dotan a su interpretación de una especial singularidad. Por ello, en el campo, pues, de la interpretación constitucional, realizada por los órganos de la justicia constitucional, es donde hoy se sitúan, verdaderamente, los problemas atinentes a la relación entre justicia constitucional y democracia. Y esos problemas no son otros que los derivados de los 
límites de la interpretación constitucional y por ello de los límites que la justicia constitucional no debe traspasar. La discusión hay que centrarla entonces en el «activismo judicial» y en el «exceso de jurisdicción» a que ese activismo tiende, que sí pueden poner en peligro el necesario equilibrio entre justicia constitucional y democracia, asuntos de los que se ya se ha venido tratando.

\section{LOS SIGNIFICADOS PROCEDIMENTAL Y SUSTANTIVO DE LA DEMOCRACIA. JUSTICIA CONSTITUCIONAL Y REFORMA DE LA CONSTITUCIÓN}

Si desechamos, por su patente inconsistencia teórica y su innegable falsedad práctica, la vieja contraposición entre democracia formal y democracia real, pues sin normas que la garanticen la democracia no es posible, solo cabe discutir en serio otra distinción relevante para el asunto de que se está tratando: la que pudiera existir entre democracia procedimental y democracia sustantiva. La primera se sostiene en el aserto de que la democracia «es procedimiento y solo procedimiento" (frase bien conocida de Kelsen, aunque en cierto modo relativizada en su obra De la esencia y valor de la democracia) y la segunda está basada en la idea de que la democracia se identifica con un conjunto de valores sustantivos que los procesos de decisión no pueden cambiar.

Una y otra versión de la democracia parten de un presupuesto común: no hay democracia fuera del derecho. Pero se distinguen en cuanto a las reglas que el derecho impone a la democracia. Para unos, el derecho solo impone la exigencia de que, para adoptar decisiones políticas, el poder público ha de someterse a los procedimientos democráticos. Para otros, lo que el derecho exige no es solo que se sigan tales procedimientos, sino que se acaten también unos valores (dignidad de la persona, derechos inviolables que le son inherentes) que quedan sustraídos a la capacidad de decidir mediante procedimientos democráticos. Y así se ha dicho, en frase gráfica y muy repetida, que «la democracia no puede ser destruida mediante procedimientos democráticos».

Este problema, como es obvio, no se plantea en el ámbito de la democracia «en» la constitución (esto es, de la democracia en el poder constituido), puesto que toda constitución exige el acatamiento no solo de unas reglas procedimentales, sino también materiales, que limitan la acción del poder del Estado. En tal sentido, la democracia «en» la constitución es procedimental y sustantiva al mismo tiempo y de manera inseparable. Donde el problema se plantea es en el ámbito de la democracia «de» la constitución (esto es, de la democracia en el poder constituyente). Para Kelsen, toda ley inconstitucional lo sería por razones formales, es decir, por no haber seguido el legislador el procedimiento de reforma de la constitución. Lo que significa que, si ese procedimiento se siguiera, la constitución podría cambiarse sin límite material 
alguno. No habría, en consecuencia, valores vedados a la capacidad de acción del soberano popular siempre que actúe a través de los procedimientos de reforma constitucional. En cambio, para los defensores de la democracia en sentido sustantivo, el poder constituyente democrático está también limitado, pues la constitución, y su reforma no podrían ser democráticas si el texto constitucional resultante no garantizase la existencia de los valores y derechos inherentes a la dignidad de la persona que son presupuesto de la democracia misma.

Dicho con otras palabras, para los defensores de la democracia procedimental, en el plano de la democracia «de» la constitución (que es una democracia de consenso) no existen límites al pluralismo político (sí, claro está, en el plano de la democracia «en» la constitución, que es democracia de mayoría), mientras que para los defensores de la democracia sustantiva el pluralismo político se encuentra limitado, no sólo en el plano de la democracia «en» la constitución, sino también en el de la democracia «de» la constitución. Este y no otro es el problema que plantean los límites materiales, explícitos o implícitos, a la reforma constitucional. Y este es, en consecuencia, el problema último con que se enfrenta la justicia constitucional, en su relación con la democracia, al controlar las reformas constitucionales.

En un Estado democrático de derecho me parece claro que la justicia constitucional tiene legitimidad para controlar la constitucionalidad de las reformas constitucionales en cuanto a comprobar si han seguido o no el procedimiento que la constitución ha establecido para su propia reforma. Si así no fuera, las normas constitucionales sobre la reforma, al carecer de la garantía jurídica de su cumplimiento, no serían constitución, aunque formaran parte de su texto. La rigidez constitucional sería, simplemente, un mandato político cuya eficacia dependería exclusivamente de la libre voluntad del poder constituyente-constituido. Es obvio que ello no puede aceptarse teóricamente, aparte de que prácticamente haría que la constitución, pese a presentarse como rígida, sería, en realidad, flexible. La supralegalidad constitucional desaparecería, y, con ello, la propia constitución en su sentido moderno, «racional-normativo» (tan bien descrito por García-Pelayo). De ahí la necesidad de admitir que la justicia constitucional posee legitimidad para controlar las reformas constitucionales por razones de procedimiento.

Cuestión distinta es si puede también controlarlas por razones de fondo, esto es, porque tales reformas alteren el sistema de valores materiales sin los cuales no cabría hablar de constitución democrática. Y aquí se abren dos perspectivas, según que la Constitución haya fijado o no, de manera expresa, límites materiales a su reforma. Si lo ha hecho, la legitimidad de la justicia constitucional para efectuar ese control de fondo es clara, por ser coherente con lo dispuesto en el mismo texto constitucional. Si no lo ha hecho, entonces la cuestión es mucho más compleja, pues nos encontraríamos con el problema 
de los límites materiales implícitos, cuya aceptación depende, a mi juicio, del modo de participación del soberano popular en la propia reforma constitucional.

En ausencia, pues, de límites materiales explícitos a la reforma, si es el pueblo soberano el que al final del procedimiento de reforma se pronuncia definitivamente sobre la misma, aprobándola, resulta muy cuestionable que la justicia constitucional pueda controlar la reforma por razones de fondo, pues el cambio constitucional lo ha sancionado el propio poder constituyente, juridificado por la constitución como poder de reforma, pero solo juridificado en cuanto al procedimiento, no en cuanto a la materia. En cambio, si ante el mismo supuesto de ausencia de límites materiales expresos a la reforma constitucional, esa participación popular directa no se da, es plausible que la justicia constitucional haya de velar por que el cambio constitucional, aprobado no por del poder constituyente juridificado, sino por el poder constituido reformador, se atenga (como poder constituido, aunque de reforma) a unos límites que, como poder delegado y no originario, tiene impedido traspasar, que operarían, interpretativamente, como límites materiales implícitos a la reforma constitucional. Ahora bien, si toda interpretación de la constitución es tarea compleja y delicada, esta de la obtención interpretativa de límites materiales implícitos a la reforma lo es mucho más, de manera que solo en supuestos de clara obtención interpretativa de tales límites y de indudable transgresión de ellos la justicia constitucional estaría legitimada para controlar la validez de la reforma constitucional por razones de fondo.

Nuevamente, en el tema de los límites implícitos, y especialmente en los casos en que no coinciden subjetivamente el poder constituyente y el poder de reforma, nos encontramos, pues, en el mismo terreno donde cabe situar la relación entre justicia constitucional y democracia: el de la capacidad y alcance de la interpretación constitucional. Si esa capacidad es libre, entonces sí que cabría sostener que la justicia constitucional se ha sobrepuesto a la democracia. Si, por el contrario, esa capacidad está subordinada a una fundamentación jurídicamente razonable, lo que habría hecho la justicia constitucional es realizar su función, legítima, de preservar la constitución, y por ello la democracia constitucional, haciendo prevalecer la democracia «de» la constitución sobre la democracia «en» la constitución.

Cuestión distinta, de naturaleza teórica y no dogmática, y por ello más propia del plano de la legitimidad que del de la validez, es la de si una reforma constitucional aprobada por el poder constituyente juridificado puede dar lugar a una eliminación de la democracia. Si así fuera, el resultado de esa reforma ya no sería una nueva constitución, sino un abandono de la concepción misma de constitución, pues en sentido propio no cabe hablar de constitución si esta no es democrática, no solo en su origen, sino también en 
su contenido. En tales casos, el control de esa reforma, que más que reforma sería ruptura (ruptura del texto y ruptura del tipo), realizada, en ausencia de límites materiales explícitos, por el poder constituyente juridificado en cuanto al procedimiento pero no en cuanto a la materia, me parece que sería una tarea que excedería de la capacidad de actuación de la justicia constitucional.

Después de ese abandono de la forma constitución (y por ello de la democracia constitucional), su recuperación únicamente podría estar en manos de los políticos y de los propios ciudadanos, que en un determinado momento contribuyeron a su desaparición y que, si cambian de idea, solo podrían hacerla valer fuera de los cauces que el derecho positivo ofrece, bien mediante acuerdos que diesen paso a un proceso pacífico de transición hacia la democracia, bien incluso resucitando los viejos derechos naturales «de resistencia»e incluso «de rebelión, frente al poder injusto». En tal situación la justicia constitucional no tendría nada que hacer, entre otras cosas porque, por el cambio constitucional, esa justicia habría desaparecido, al menos en su significado auténtico.

En resumen, incluso en este supuesto límite, se hace patente, una vez más, que justicia constitucional y democracia constitucional no son realidades contradictorias, sino inseparables. No puede ser la una sin la otra.

\section{EL PROBLEMA DE LAS RELACIONES ENTRE JUSTICIA CONSTITUCIONAL Y DEMOCRACIA NO RADICA TANTO EN LA EXISTENCIA DE LA PRIMERA, SINO EN SU MODO DE ACTUAR}

Como he intentado explicar a lo largo de este trabajo, carece de sentido plantearse la relación entre justicia constitucional y democracia en términos de contradicción insalvable, puesto que, en la democracia constitucional, la justicia constitucional es requisito de la misma democracia.

El auténtico problema de esa relación, y no importa reiterarlo una vez más, ya no se sitúa en la existencia de la justicia constitucional, sino en su modo de actuar. Si ese modo se realiza sin caer en el activismo judicial, sometiéndose a los límites jurídicos que la interpretación de la constitución impone y sin excederse de la función jurisdiccional, que permite controlar a los poderes públicos, pero no sustituirlos, no cabe hablar de contraposición entre democracia y justicia constitucional. $\mathrm{Si}$, por el contrario, ambas condiciones no se observan, entonces sí que podría tacharse a la justicia constitucional de actuar de manera poco respetuosa con la democracia.

Ese es el desafío que ha de afrontar la justicia constitucional, y solo si lo gana, esto es, si no pierde la única legitimidad que la sostiene, que no es otra que la fundamentación en derecho de sus decisiones, podrá mantenerse como lo que es y debe ser: la institución imprescindible para garantizar la efecti- 
va vigencia de la constitución, que es un marco, además, en que los valores y principios constitucionales trascienden hoy el ámbito de las jurisdicciones nacionales como consecuencia del proceso de internacionalización de los derechos humanos, de manera que, en nuestros días, el constitucionalismo ha adquirido una dimensión global, convirtiéndose en una especie de ius commune de los países civilizados. Por cierto, ese fenómeno es lo que permite también dotar de objetividad, no solo teórica sino también práctica, a la teoría general de la constitución.

El constitucionalismo global de nuestro tiempo se sustenta, precisamente, en el entendimiento más correcto de la democracia constitucional, que consiste no solo en la existencia de procesos electorales libres, competitivos y transparentes, sino también en la garantía de que tales procesos no pueden conducir a la erradicación de unos valores sustantivos que, por fortuna, no pertenecen al mundo discutible de las ideas políticas, sino que han sido concretados en reglas jurídicas compartidas por las constituciones nacionales y los tratados y convenios sobre derechos humanos, que están protegidas, en los ámbitos internos y en los internacionales o supranacionales, por auténticos tribunales. La garantía jurisdiccional de los derechos humanos y de la forma de Estado democrática se ha supraestatalizado, al menos en determinados ámbitos geográficos. Esa es la nueva realidad.

La justicia constitucional de los Estados ha de acomodarse, pues, a esa nueva realidad, que ha conformado una justicia constitucional global o «multinivel» y que obliga a una leal cooperación y un continuo diálogo entre los órganos internos y los órganos internacionales o supranacionales que tienen encomendada esa común tarea. Esta globalización no puede verse como un debilitamiento de la justicia constitucional estatal, sino como un refuerzo de su eficacia, en cuanto que la cooperación recíproca ya aludida (que se sustenta en una comunidad de reglas, principios y valores) enriquece (y permite objetivar) la función que unos y otros tribunales desempeñan.

Que en el futuro se mantenga esta fértil conjunción de garantías de la democracia constitucional como sistema depende, en primer lugar, de la resistencia de la democracia constitucional frente a los peligros que la acechan, representados hoy por los movimientos fundamentalistas y populistas cuyo objetivo no es otro que destruirla; en segundo lugar, del cuidado que se ponga en la designación de los miembros de los órganos jurisdiccionales de garantía, de manera que se seleccione a juristas de reconocida competencia y se evite cualquier apariencia de parcialidad, y, por último, del funcionamiento adecuado de esos órganos, tanto los nacionales como los internacionales o supranacionales, que no deben adoptar sus decisiones mediante un acto de voluntad, sino de razón, de razón jurídica. Solo la rigurosa fundamentación de sus resoluciones hace aceptable el ejercicio de unas facultades de tan alto 
relieve como las que tales órganos tienen atribuidas, entre ellas las del control de las decisiones de la representación popular residenciada en el Parlamento.

De las resoluciones que dicten podrá discreparse, por supuesto (incluso en el interior del órgano mediante votos particulares), pero siempre ha de exigirse que la argumentación que el órgano jurisdiccional emplee para fundamentarlas esté suficientemente razonada en términos de derecho, de manera que también, razonablemente, pueda ser criticada por la comunidad jurídica, pues tal crítica supone el contrapeso más eficaz al ejercicio de la ingente potestad que la justicia constitucional ejerce. Al fin y al cabo, la justicia constitucional (como el Estado constitucional democrático a cuya conservación sirve) solo puede funcionar allí donde existe una auténtica cultura política y jurídica constitucional, lo que presupone una sociedad mayoritariamente convencida de que democracia y Estado de derecho son realidades indisociables. Por ello, la efectividad de los derechos de los ciudadanos y el correcto funcionamiento de la instituciones deben buscarse siempre dentro y no fuera de las reglas que la propia constitución proporciona y de aquellas otras que cabe deducir de su texto mediante una rigurosa interpretación. Si ello no fuera suficiente, la alternativa es reformar la constitución, pero de ninguna manera tergiversarla o destruirla.

\section{EL FUTURO DE LA JUSTICIA CONSTITUCIONAL ESPAÑOLA}

\section{JUSTICIA CONSTITUCIONAL Y JURISDICCIÓN CONSTITUCIONAL}

El sistema español de justicia constitucional pertenece, como es sabido, al modelo europeo de jurisdicción concentrada, que no es, exactamente, el que Kelsen originariamente había defendido, dado que hoy no existen dos jurisdicciones separadas por el derecho que aplican, una, la constitucional, que aplicaría exclusiva y excluyentemente la constitución, y otra, la ordinaria, que solo podría aplicar las leyes; ni por los actos sometidos a control, las leyes en la primera y las demás normas y actos en la segunda; que era el primitivo esquema kelseniano.

Entre nosotros, y lo mismo sucede en los países europeos tributarios de ese modelo, la Constitución es hoy norma jurídica que, a diferencia de lo auspiciado originariamente por Kelsen, han de aplicar todos los jueces y tribunales, de manera que la jurisdicción ordinaria, al resolver cualquier proceso, ha de garantizar la vigencia de la Constitución, pudiendo anular los actos y normas reglamentarias que la vulneren, además de que debe interpretar las leyes y reglamentos de conformidad con las prescripciones constitucionales. Lo único que no le está permitido hacer es controlar la constitucionalidad de las 
leyes, que ello está atribuido, en monopolio, al Tribunal Constitucional, que además tiene la exclusiva en el control de los actos políticos parlamentarios y la resolución de conflictos entre órganos constitucionales. Frente a las leyes inconstitucionales, la obligación de no aplicarlas se resuelve en la jurisdicción ordinaria mediante el planteamiento de la cuestión de inconstitucionalidad ante el Tribunal Constitucional, que es una vía, fundamental, de colaboración de la jurisdicción ordinaria con la tarea del Tribunal Constitucional de controlar la constitucionalidad de las leyes.

En nuestro sistema de justicia constitucional, la jurisdicción del Tribunal Constitucional se caracteriza porque le corresponde la suprema interpretación de la Constitución, debiendo los jueces y tribunales ordinarios aplicar la doctrina emanada por el Tribunal en toda clase de procesos de que entiende. También porque tiene en monopolio, como se ha dicho, el control de constitucionalidad de la ley e incluso de normas infralegales y de determinados actos impugnables ante el Tribunal mediante el conflicto de competencias territoriales, las impugnaciones directas previstas en el título V de la LOTC, el conflicto entre órganos constitucionales y el recurso de amparo.

En consecuencia, debe distinguirse entre la justicia constitucional, que no es otra cosa que la aplicación judicial de la Constitución, y que en España llevan a cabo el Tribunal Constitucional y todos los jueces y tribunales ordinarios, y la jurisdicción constitucional, que es la atribuida en exclusiva al Tribunal Constitucional a través de los procesos de que conoce. Esta distinción formal, procesal, si se quiere, entre nuestras dos jurisdicciones, no se corresponde plenamente con una distinción material, pues, salvo en el control de la ley (ya sea de modo previo respecto de tratados y reformas estatutarias, ya sea resolviendo recursos y cuestiones de inconstitucionalidad e incluso conflictos en defensa de la autonomía local), en el conflicto entre órganos constitucionales y en el recurso de amparo frente a actos parlamentarios sin valor de ley, en los demás casos los actos y normas que, por razones de constitucionalidad, pueden ser controlados por el Tribunal Constitucional también lo pueden ser por la jurisdicción ordinaria.

\section{EL FUTURO DE LA JUSTICIA CONSTITUCIONAL DESEMPEÑADA POR LOS JUECES Y TRIBUNALES ORDINARIOS}

Los órganos integrantes de nuestro Poder Judicial han cumplido de manera muy satisfactoria su cometido de aplicar la Constitución en toda clase de procesos. Hubo, no obstante, hace años, cierta tensión entre el Tribunal Supremo y el Tribunal Constitucional en relación con la delimitación de ambas jurisdicciones, pero ese problema creo que ya puede darse por resuelto. Lo que no significa ignorar que hay algunas zonas de posible colisión entre la 
jurisdicción ordinaria y el Tribunal Constitucional, debidas a la confluencia material que, en determinados ámbitos de conocimiento, existe entre las dos jurisdicciones. Para evitar, o minimizar, esas colisiones es preciso que ambas jurisdicciones tengan claros dos postulados inherentes a nuestro sistema: a) que el Tribunal Constitucional, supremo intérprete de la constitucionalidad de la ley, no revise la interpretación legal del Tribunal Supremo salvo en los casos en que su contradicción con la Constitución sea indiscutible, aplicando la máxima de que «en caso de duda, a favor del Tribunal Supremo», y b) que los jueces y tribunales ordinarios acaten sin reparo alguno la doctrina sobre la interpretación de la Constitución y la interpretación constitucional de la ley establecida por el Tribunal Constitucional, con el que deben colaborar planteando las cuestiones de inconstitucionalidad y evitando la tentación de controlar al legislador.

Dicho lo anterior, no puede ocultarse que hoy los órganos judiciales ordinarios pueden inaplicar leyes por su contradicción con el derecho de la Unión Europea, pero eso no significa que tengamos una justicia difusa de la constitucionalidad de la ley, sino una justicia difusa de su adecuación al derecho europeo, ámbitos que pueden deslindarse siempre que tanto los jueces y tribunales ordinarios como el Tribunal Constitucional no los confundan. Para evitar esa confusión es preciso que la cuestión de inconstitucionalidad y la cuestión prejudicial no se interfieran.

Por último, y referido solo a la labor de la jurisdicción ordinaria en el control de constitucionalidad de actos y normas infralegales, en concreto, la tutela de los derechos fundamentales, cabe apuntar que, respecto de los derechos susceptibles de amparo ante el Tribunal Constitucional, la actual regulación del incidente de nulidad de actuaciones, como remedio procesal previo al amparo, no contribuye precisamente a potenciar aquella tutela por la jurisdicción ordinaria. Tal como está previsto, se trata de una impugnación horizontal (ante el mismo órgano judicial que adoptó la última decisión) y sin intervención del Ministerio Fiscal, que hace prácticamente inoperante tal remedio, con la consecuencia de que ni descarga de trabajo al Tribunal Constitucional ni facilita que las vulneraciones de derechos producidas en la última decisión judicial puedan ser depuradas (y por ello esos derechos tutelados) por la propia jurisdicción ordinaria.

De ahí la conveniencia de que se reforme el procedimiento de ese incidente, transformándolo en un remedio vertical, de manera que siempre entienda del mismo el órgano judicial superior del que dictó la última resolución (si procedió del Tribunal Supremo, en el caso de secciones, la sala, en el caso de la sala, el pleno, y en el caso del pleno, el órgano previsto en el art. 61 de la Ley Orgánica del Poder Judicial —en adelante, LOPJ—) e intervenga necesariamente el Ministerio Fiscal, que por mandato constitucional y por 
exigencias de su Estatuto Orgánico ha de actuar en los procesos en defensa de los derechos fundamentales, y este incidente lo es.

\section{EL FUTURO DE LA JUSTICIA CONSTITUCIONAL DESEMPEÑADA POR EL TRIBUNAL CONSTITUCIONAL}

Creo que puede sostenerse, con objetividad, que la labor desarrollada por el Tribunal Constitucional ha sido muy positiva en su tarea de supremo intérprete y defensor jurídico de la Constitución. Más aún, ha de reconocerse que el Tribunal Constitucional ha sido, y sigue siendo, la institución fundamental para garantizar y desarrollar los derechos fundamentales, y absolutamente necesaria para la construcción y funcionamiento de nuestro complejo Estado autonómico (Aragón, 1986).

Es cierto que algunas de sus decisiones pueden ser criticables (y ello, creo, queda dentro de la normalidad), pero en términos generales la inmensa mayoría de ellas han sido plenamente acertadas, y todas, sin excepción, suficientemente razonadas en derecho. La existencia, en nuestro ordenamiento, de los votos particulares, ha contribuido, además, a hacer más transparente las resoluciones del Tribunal, a fomentar su crítica (algo siempre conveniente, más aún, necesario) y a propiciar cambios de jurisprudencia.

El elenco de competencias de nuestro Tribunal también parece el adecuado en términos generales (salvedad hecha de que alguna de ellas pueda ser criticable, como la de atribución en exclusiva al Tribunal del control de constitucionalidad de las normas fiscales forales vascas) y su composición (en la línea del modelo europeo de tribunales constitucionales) no resulta inapropiada, aunque precise, a mi juicio, de ciertos cambios concretos a los que también después me referiré.

Dicho lo anterior, y pensando en el futuro de la institución, no cabe ocultar que ese futuro, en primer lugar, está inevitablemente unido al futuro de nuestra democracia constitucional, como ya advertí desde el comienzo mismo de este trabajo, y, en segundo lugar, que si pese a la crisis que hoy está experimentando la democracia constitucional en España (y en otros países), esa crisis se remonta (como es de esperar) y aquella democracia se conserva (e incluso se mejora), ello no asegura por completo que el Tribunal Constitucional pueda mantenerse en el ejercicio eficaz de sus funciones. Para que eso se logre es preciso que aumente y no disminuya su legitimidad, ya que solo en ella puede descansar el desempeño aceptable de las supremas potestades que le están atribuidas.

Por ello, voy a referirme brevemente a algunas medidas que, para garantizar el buen futuro del Tribunal, debieran adoptarse, o, incluso, a determinadas condiciones que siempre debieran mantenerse con el mayor rigor. Dado el 
carácter general del presente trabajo, solo voy a referirme a las que creo más importantes (eludiendo a otras que posiblemente requerirían de cambios en la propia jurisprudencia del Tribunal, por ejemplo, las relativas a la situación creada, y criticable, a mi juicio, por las SSTC 102/2016, 116/2016 y 127/2016 sobre la prevalencia, y la STC 118/2016 sobre el control de constitucionalidad de las normas fiscales forales vascas).

a) La erradicación del sistema de cuotas entre partidos a la hora de la designación de los magistrados constitucionales; bien por abandono de esa práctica política, que por sí sola no origina necesariamente politización, pero que sí genera una «apariencia» de politización que no beneficia la legitimación del Tribunal, volviéndose a la regla del consenso que se aplicó en la primera composición que este tuvo; bien, si ese cambio de práctica no se produjera, acudiéndose a una modificación normativa (posiblemente en los reglamentos del Congreso y el Senado) para imponer un procedimiento (y habría fórmulas para ello) que obligase al consenso, o, en último extremo, si ninguno de esos cambios fuesen posibles, acudiendo a un remedio radical: reformar la Constitución para establecer un mandato de los magistrados constitucionales que duraría hasta que cumplieran la edad de 75 años, con lo cual, además de asegurarse mejor su independencia, se eliminarían las actuales renovaciones por tercios cada tres años (solo habría las individuales producidas por la terminación del tiempo de mandato o por fallecimiento o renuncia), con lo cual desaparecería el sistema de cuotas, tan unido al modo actual de renovación.

b) La exigencia de una rigurosa selección de los magistrados constitucionales para que, efectivamente, siempre lo sean entre «juristas de reconocida competencia", concepto jurídico indeterminado que, no obstante, es objetivamente determinable en cada caso. Para controlar que ello sea así, está previsto precisamente el control sobre la idoneidad de los magistrados propuestos, atribuido al propio Tribunal Constitucional por el art.2.1.g) LOTC. El desempeño fiel y eficaz de ese control que el Tribunal tiene atribuido es, en mi opinión, la última garantía para que a él lleguen personas de probada experiencia y reconocida excelencia en el mundo del derecho.

c) La eliminación de los excesivos retrasos que, pese a los esfuerzos realizados en los últimos años, aún tienen algunos asuntos pendientes en el Tribunal, lo que es posible si se organiza bien el trabajo interno y se agilizan las deliberaciones. Precisamente la última reforma del recurso de amparo, en 2007, facilita que el Tribunal pueda dedicar más tiempo a los demás procesos constitucionales, entre ellos los recursos y cuestiones de inconstitucionalidad, que es donde ahora (y siempre) residen los más largos retrasos en resolver. Acrecentar la eficacia y prontitud de la respuesta del Tribunal acrecentará, sin duda, su legitimación. 
d) La reducción, en la medida de lo posible, de las sentencias interpretativas para no contribuir a las situaciones de inseguridad jurídica que, a veces, suelen producir, y, sobre todo, para que el Tribunal evite convertirse en legislador positivo, lo que no se corresponde con su naturaleza jurisdiccional. La interpretación constitucional de las leyes, que es, por supuesto, una obligación, tiene límites derivados del tenor inequívoco de los preceptos legales, límites que no debieran traspasarse, pues el Tribunal está para controlar las leyes, no para legislar.

e) Por último, y en relación con el nuevo amparo, cuya objetivación no ha hecho desaparecer su función también de tutela de derechos, creo que es necesario que se extreme el rigor en la admisión, pues solo así se preserva su nuevo significado y, al mismo tiempo, su funcionalidad respecto de las demás competencias del Tribunal.

\section{CONCLUSIONES}

Si tenemos en cuenta la actual situación de globalización en materia económica, de universalización e incluso, en determinadas zonas geográficas, de supraestatalización en materia de derechos humanos, fenómeno este último que se ha manifestado en América y Europa principalmente y que ha llevado a la implantación de órganos jurisdiccionales trasnacionales de garantía de esos derechos, como son el Tribunal Interamericano de Derechos Humanos y el Tribunal Europeo de Derechos Humanos, y si reparamos, además, que en ciertos países, los que componen la Unión Europea, en la que España está integrada, las exigencias de respeto a los principios democráticos y a los derechos constitucionales vienen impuestas por instancias superiores a ellos, cabe plantearse cuál será el futuro, en tales condiciones, de la justicia constitucional.

La respuesta no es difícil: el mismo futuro de las constituciones. Es decir, de igual manera que las constituciones de los Estados han de atenerse a la globalización económica si quieren ser normas eficaces y no puramente nominales o semánticas, no permanecer ajenas a la internacionalización de los derechos humanos, e incluso algunas aceptar la supraestatalización de los derechos fundamentales y de la forma de Estado democrático y de derecho, que son condiciones que les vienen impuestas, la justicia constitucional ha de acomodarse a esa nueva realidad. Hoy se habla incluso de una justicia constitucional «multinivel», que es un término poco aseado lingüísticamente pero que expresa bien la existencia de jurisdicciones de garantía que exceden en su ámbito el de los Estados, pero que son un complemento de las jurisdicciones internas. 
De manera que hoy, al menos en determinadas zonas del mundo, la justicia constitucional de cada Estado ha de imbricarse en ese sistema de justicia constitucional supraestatal. Se ha producido una suerte de derecho constitucional común que obliga al diálogo permanente (expreso o implícito) entre jurisdicciones constitucionales de determinado conjunto de Estados y entre esas jurisdicciones y los órganos internacionales o supranacionales de garantía. En resumen, la justicia constitucional ha de acomodarse a esas nuevas circunstancias. Ello, a mi juicio, no tiene por qué dar lugar al debilitamiento de su función, sino al reforzamiento de su eficacia, siempre que se mantengan los requisitos cuyo cumplimiento la sostienen. Y ahí sí que se juega el futuro la justicia constitucional.

Porque, a diferencia de los órganos políticos, los órganos de la justicia constitucional, y en especial los tribunales constitucionales, no adoptan sus decisiones por un acto de voluntad, sino de razón, esto es, de razón jurídica. Solo la rigurosa fundamentación jurídica de sus resoluciones hace aceptable el ejercicio de unas facultades de tan alto relieve, entre ellas, el control del legislador democrático. De esa fundamentación podrá discreparse, por supuesto, pero es exigible que la argumentación que el órgano jurisdiccional emplee siempre esté suficientemente razonada en términos de derecho.

Como ya se examinó más atrás, hoy la vieja polémica, protagonizada en los años veinte del pasado siglo, entre otros, por Carl Schmitt y Hans Kelsen, acerca de la naturaleza política o jurídica de las decisiones del órgano que desempeña la jurisdicción constitucional ha de darse por resuelta, pese que a que en algunos sectores, más por ignorancia que por conocimiento crítico, vuelva a surgir de cuando en cuando. La importancia política de los pronunciamientos de un tribunal constitucional (o del Tribunal Supremo norteamericano, por poner el ejemplo de otro modelo) es incuestionable, al menos en los asuntos de mayor calado. Pero ello no excluye que esos pronunciamientos dejen de ser sobre asuntos de derecho y, en consecuencia, resueltos a través de las reglas de la interpretación jurídica. Una interpretación jurídica que, cuando ha de recaer sobre la constitución, dada la densidad normativa y generalidad de muchos de sus preceptos, es más compleja (aunque no completamente distinta) que la que tiene por objeto la ley, y de ahí la necesidad de que los órganos de la jurisdicción constitucional sean ocupados por juristas expertos en esa difícil tarea.

De igual modo, el socorrido argumento del carácter contramayoritario de sus decisiones para poner en cuestión la existencia misma de los tribunales constitucionales resulta de muy escasa entidad, siempre que se acepte un punto de partida insoslayable; que la constitución limita a los poderes constituidos, y por ello al legislador. De la misma manera que no pueden contraponerse constitución y democracia, tampoco pueden contraponerse 
justicia constitucional y democracia, si esa relación se plantea y examina adecuadamente, como también ya se trató en la primera parte del presente trabajo. Quien opone democracia a constitución, aparte de ignorar la naturaleza y eficacia de la constitución, confunde, gravemente, la democracia como idea con la democracia constitucional como concepto. En la democracia constitucional, democracia y Estado de derecho son, tienen que ser, realidades indisociables. La constitución democrática, que es la única constitución auténtica, se caracteriza por que sus reglas se imponen frente a la mayoría parlamentaria, esto es, porque el legislador no es soberano ni lo es tampoco cualquier otro poder público central o territorial, que han de estar sometidos a las reglas y principios que la constitución ha establecido y que el tribunal constitucional o los tribunales ordinarios en los modelos de jurisdicción difusa deben garantizar cuando para ello sean requeridos.

A partir de ese postulado, los conflictos entre la constitución, como norma jurídica suprema, y las demás normas y actos del poder solo pueden ser resueltos, si se quiere conservar el principio de la seguridad jurídica, por un órgano jurisdiccional. Bien sabemos, desde hace siglos, que no hay derecho (objetivo o subjetivo) sin la existencia de jueces que lo garanticen. Esa es la razón por la que la aplicación última de la constitución ha de dejarse en manos de órganos jurisdiccionales y no políticos. Cosa distinta es el modo en que los órganos de la jurisdicción constitucional apliquen la constitución, y ahí sí tiene todo el sentido la crítica, no a la existencia de esos órganos, sino a su inadecuada composición o al incorrecto ejercicio de sus funciones. Incorrección esta que puede llegar en los casos extremos a la fundamentación de sus decisiones en argumentos políticos, morales o sociales, pero no jurídicos. Ello, por fortuna, como ya se dijo más atrás, es infrecuente en los Estados constitucionales con una cultura jurídica consolidada, en los que, sin embargo, sí es menos raro que aquellas decisiones se produzcan a veces a través de una motivación en derecho de escasa solidez, defecto del que la justicia constitucional debe huir porque, indefectiblemente, la desacredita.

De la eficacia en el desempeño de su función, y ello exige evitar excesivos retrasos en resolver, así como también exige una redacción clara y concisa de las decisiones que adopten; de la desaparición de cualquier apariencia de parcialidad, y ello exige una cuidadosa y despolitizada selección de quienes la desempeñan, pero, sobre todo, de la legitimidad de sus pronunciamientos, y ello exige que estén bien razonados en derecho, dependerá el buen o mal futuro de la justicia constitucional, que es lo mismo que decir el buen o mal futuro de la constitución. Un éxito o un fracaso cuya responsabilidad recae en los poderes políticos que regulan esas instituciones, pero también en el modo de actuar de quienes las desempeñan. 
También hay que decir que no contribuye precisamente a afianzar el futuro de cualquier tribunal constitucional (incluido el nuestro) el hecho, criticable, de que se trasladen, permanentemente, a él conflictos políticos que deben tener su solución en otras instancias, pues, sin perjuicio del derecho innegable, e incluso la obligación, de impugnar leyes (u otras normas y actos) por razones de inconstitucionalidad, parecería un manifiesto abuso convertir a la jurisdicción constitucional en una especie de tercera Cámara a la que acuda habitualmente la oposición para intentar ganar allí la batalla que en el Parlamento perdió, o a la que acudan los Gobiernos para endosar al tribunal constitucional determinadas decisiones que ellos no se atreven a tomar pese a tener suficientes competencias para ello. Esa tendencia, muy patente en España, debiera eliminarse o, cuando menos, reducirse, pues, si se intenta judicializar la política, ambas funciones acaban resultando perdedoras.

Por último, no cabe ocultar que otra condición para que en el futuro se mantenga la justicia constitucional es la de asegurar que sus decisiones se cumplan, de manera que los órganos que la desempeñan posean las competencias suficientes para hacer efectiva la plena ejecución de sus resoluciones. Administrar justicia es juzgar y ejecutar lo juzgado. Esa competencia, que la tiene cualquier órgano de la jurisdicción ordinaria, han de tenerla, y ejercerla, también los órganos supremos de la jurisdicción constitucional. Así sucede en la inmensa mayoría de los demás países con justicia constitucional consolidada, y así debiera suceder en el nuestro.

Termino este trabajo, como acaba de verse, con una alusión a la situación española, y ello es debido a la preocupación que me embarga, pensando en el futuro de nuestro Tribunal Constitucional, porque desde ciertos sectores, incluidos algunos académicos, haya podido ponerse en duda la oportunidad e incluso la corrección de dotar a ese Tribunal de poderes suficientes para hacer cumplir sus resoluciones. Una cosa es que puedan criticarse los términos imprecisos con que está redactada alguna de las medidas concretas que al efecto se han establecido recientemente, y otra bien distinta que se pretenda que el Tribunal no pueda por sí mismo asegurar el cumplimiento de sus resoluciones y tenga que quedar para ello a expensas de otros poderes del Estado. Sin perjuicio del auxilio que ellos deberán prestar al Tribunal, a él y solo a él, como auténtico Tribunal, le corresponde la tarea de garantizar el pleno ejercicio de su jurisdicción, lo que significa que ha de gozar de las potestades suficientes para hacer cumplir sus decisiones. Así lo ha entendido, finalmente, el propio Tribunal Constitucional en sus sentencias 185 y 215/2016, desestimatorias de los recursos de inconstitucionalidad interpuestos contra la Ley Orgánica 15/2015, de 10 de octubre, sobre regulación de la ejecución de las resoluciones del Tribunal Constitucional en garantía del Estado de derecho. Unas sentencias 
que, como todas, pueden ser discutibles (prueba de ello son los tres votos particulares que las acompañan) pero que a mí me parecen bastante razonables.

Ninguna institución tiene su futuro, por siempre, asegurado, pero tengo la convicción, que he querido trasladar en estas páginas, de que el futuro de la justicia constitucional, y en especial el futuro de nuestro Tribunal Constitucional, que no lo veo radicalmente en peligro, estará mucho más despejado si se adoptan las medidas y se evitan los riesgos que he venido mencionando a lo largo de este trabajo.

\section{Bibliografía}

Aragón, M. (1986). ¿Estado jurisdiccional autonómico? Revista Vasca de Administración Pública, 16, 7-12.

(2013). Estudios de Derecho Constitucional. Madrid: Centro de Estudios Políticos y Constitucionales.

Rodríguez Garavito, C. y Rodríguez Franco, D. (2010). Un giro en los estudios sobre derechos sociales: el impacto de los fallos judiciales y el caso del desplazamiento forzado en Colombia. En P. Arcidiácono, N. Espejo y C. Rodríguez (coords.). Derechos sociales: justicia, política y economía en América Latina (pp. 83-154). Bogotá: Siglo del Hombre Editores. 